\title{
Cost effectiveness and equity of a community based cardiovascular disease prevention programme in Norsjö, Sweden
}

\author{
Lars Lindholm, Måns Rosén, Lars Weinehall, Kjell Asplund
}

\begin{abstract}
Study objective - To evaluate the cost effectiveness and equity of a community based cardiovascular disease prevention programme.

Design - A prospective cross sectional design.

Setting - A community based intervention to reduce cardiovascular disease in the district of Norsjö $(n=5500)$, Sweden. The intervention was aimed at both the general population and at individuals thought to be at special risk, the emphasis being on changing dietary habits and reducing cholesterol concentrations.

Participants - The participants were men and women aged 30-60 years.

Main results - The mean serum cholesterol concentration in the Norsjö population was reduced by nearly $20 \%$ during the first six years of intervention. It was estimated that the programme's overall total societal costs were $£ 363000$ and estimates of the cost per year of life saved ranged from $£ 14900$ to net savings, according to different assumptions. Taking only health care costs and savings into account, the cost per year of life saved ranged from $£ 1100$ to $£ 4050$. The results varied between different sex and age groups, but not between social classes. Even if a causal relationship exists between low cholesterol concentrations and excess mortality, the estimated side effects of lowering cholesterol values in Norsjö were negligible in comparison with the expected benefits.
\end{abstract}

Conclusions - The community based intervention in Norsjö seems to be cost effective even under conservative assumptions. The approach used seems to have benefited all social classes. Cost effectiveness analyses that take consequences for equity into account are valuable tools in decision making.

\section{(f Epidemiol Community Health 1996;50:190-195)}

The prevalence of cardiovascular disease is high in northern Sweden. In 1985 an intervention programme was started in the county of Västerbotten (260 000 inhabitants). The programme was first initiated in Norsjö, a rural authority with an $80 \%$ excess mortality rate in cardiovascular disease for men compared with the national average ${ }^{1}$ and crude prevalences of hypercholesterolaemia $(\geq=6.5 \mathrm{mmol} / \mathrm{l})$ of $59 \%$ for men and $53 \%$ for women aged $30-60$ years of age. ${ }^{2}$ The starting point of the Norsjö programme was a community diagnosis which showed the above mentioned excess mortality in cardiovascular disease. This finding gave rise to demand for action against cardiovascular disease from the local authorities. In January 1985, planners, politicians, local representatives of some 100 voluntary organisations, primary care personnel, researchers, and journalists were gathered for a "kick off" meeting. After two months a local action group was started in Norsjö, supported by a scientific reference group at the Umeå University. The strategy was to involve the population; opinion leaders were motivated, the press was informed, and local study material was prepared. This population strategy was combined with educational screening and advice from health care personnel.

The programme in Norsjö comprised health promotion activities undertaken in the community by adult educational associations, sports clubs, media, food retailers (food labelling), companies, and local authorities combined with screening and followed by appropriate advice focussed on the main risk factors for cardiovascular disease.

A crucial question in this and other community programmes designed to prevent cardiovascular disease is whether they are cost effective. Cost effectiveness evaluations are hampered by a lack of data on changes in morbidity and mortality in the population. Therefore, in provisional evaluations, effects will have to be deduced from intermediate end points - that is, risk factors. In controlled trials, the effects of blood pressure reduction in bringing down cardiovascular morbidity and mortality have been amply demonstrated, whereas the effects of various lipid lowering regimens are more controversial. ${ }^{3-9}$ As for cessation of smoking, evidence for cholesterol is based on observational studies, ${ }^{410-12}$ but a recent randomised trial shows effects on coronary heart disease. ${ }^{13}$ However, it is unclear to what extent experiences from clinical trials can be applied to entire populations.

Epidemiological community based studies have convincingly shown that high blood pressure, serum cholesterol, and smoking are related to the risk of coronary heart disease. ${ }^{1014}$ A reasonable strategy in provisional evaluations would be to assume that these relationships also prevail in community based intervention programmes. In the present study, costs and potential effects have been quantified in middle aged men and women, based on observations made in the Norsjö study. 


\section{Methods}

From 1985, all individuals in Norsiö (total population 5500) entering their $31 \mathrm{st}, 41 \mathrm{st}$, $51 \mathrm{st}$, and 61 st years were invited to be screened for cardiovascular risk factors (in 1985, age classes born 1925, 1935, 1945, 1955 and in 1986, age classes born in 1926, 1936, 1946, 1956 etc). After the screening, health care staff gave advice on lifestyle factors based on the results. There was a $95 \%$ participation rate in the screening programme. The present study is based on all screening done in the years 1985-90. In all, 1498 individuals were screened. Screening was performed annually, in the late autumn, by the same group of trained nurses. The screening phase comprised a questionnaire and a health examination.

Inviting everyone who reaches a specific age to be screened once means that is not possible to measure the direct effects of screening. However, it is possible to measure the indirect dissemination effect of the screening and the effects of the other health activities (for example, food labelling).

In the analyses we used data on total cholesterol, diastolic blood pressure, smoking habits, and occupation. Three social groups were distinguished by occupation, using the Swedish socioeconomic classification. ${ }^{15}$

The counties of Norrbotten and Västerbotten in northern Sweden (total population of 510000 ) served as a reference area so that we could make a comparison with general trends. This population is one of those studied in the WHO MONICA project. A total of 2000 inhabitants aged 25-64 years from the reference area, were randomly selected (age stratified) from the population registers in 1986 and 1990 and invited to take part in a screening examination for cardiovascular risk factors. The northern Sweden MONICA screening procedures have been described elsewhere. ${ }^{16}$ In the 1986 screening (January-April), 1625 (81.3\%) people participated and in the 1990 session, $1583(79 \cdot 2 \%)$ took part.

Logistic regression equations from the Framingham study for men and women ${ }^{10}$ were used to estimate the risk of coronary heart disease for every individual. The regression equation estimates the eight year cumulative incidence for coronary heart disease. In multivariate regression models, time trend and social group were included as independent variables with cumulative incidence as a dependent variable. An earlier study ${ }^{2}$ has assessed the changing social pattern of cardiovascular disease, and found that the reduction of risk for hypercholesterolaemia between 1985 and 1990 was approximately equally large in social classes 1 and 3 . Since the crude prevalence of risk factors were higher in social group 3 , one can expect a more pronounced decrease in risk for coronary heart disease in this group due to the exponential form of the risk function. Therefore, both an intercept shift variable and a slope shift variable ${ }^{1718}$ were used for each social group.

The cumulative incidence was predicted, based on all individual observations, for the beginning and the end of the $1985-90$ period. The number of cases for 1990-98 was predicted in two alternatives (with and without community intervention) and the Norsjö population of 1990 in the age range 25-64 years was used for both predictions. The difference in the number of cases was defined as the maximum intervention effect. The distribution of the maximum number of prevented cases was assumed to be symmetrical, with an eighth of them appearing each year. The number of cases prevented was separated into definite or possible myocardial infarction, angina pectoris, and sudden death. All cases of sudden death and $40 \%$ of definite myocardial infarctions were assumed to be fatal in accordance with results from the population based northern Sweden MONICA study. ${ }^{19}$

There is a time lag between decreasing cholesterol and decreasing incidence. Law et $a l^{20}$ estimated the time lag between the decrease in cholesterol and the full effect to be five years, although a substantial effect is obtained after only two to three years. We assumed a gradually increasing "fraction of benefit", a proportion between 0 and 1 . We assumed that in the population as a whole the fraction of benefit was 0 in $1985-87$ and 0.2 in 1988 , after which linear growth to 1 in 1995 was assumed. After 1995 we assumed two different courses. In one alternative the effect remained at the 1995 level (fraction of benefit $=1$ ) and in the other it decreased to 0.5 in 1998 . In sensitivity analyses we considered regression dilution bias. ${ }^{1121}$

The potential risk of excess mortality caused by low cholesterol concentrations was estimated. Jacobs et $a l^{4}$ reported that the risk of all causes mortality was $14-22 \%$ greater for men with cholesterol $<160 \mathrm{mg} / \mathrm{dl}(\leq 4.15 \mathrm{mmol} / \mathrm{l})$ than for those with cholesterol $160-199 \mathrm{mg} / \mathrm{dl}$. For women, the risk was constant across cholesterol levels. We assumed an excess mortality risk of $50 \%$ when cholesterol was $\leq=4 \cdot 15$ $\mathrm{mmol} / \mathrm{l}$. An increasing proportion of the population had a low cholesterol between 1985 and 1990 and was assumed to be a consequence of the intervention.

Costs for the programme have been presented elsewhere. ${ }^{22}$ The estimated costs of screening are based on time measurements, and time for planning and admissions are included

Table 1 Cost components (price level $=1992$, £1 sterling =12 Swedish kroner)

\begin{tabular}{|c|c|c|}
\hline & Per year & \\
\hline \multirow[t]{2}{*}{$\begin{array}{l}\text { Screening ( } 250 \text { participants): } \\
\text { Labour and laboratory costs } \\
\text { Participation time cost } \\
\text { Population measures: }\end{array}$} & $\begin{array}{c}11150 * \dagger \\
9550 \ddagger\end{array}$ & \\
\hline & & \\
\hline \multirow{7}{*}{$\begin{array}{l}\text { Dietician } \\
\text { Marking of groceries } \\
\text { The authority } \\
\text { Study circles } \\
\text { Total direct } \\
\text { Total indirect } \\
\text { Total }\end{array}$} & $14500 * \dagger$ & \\
\hline & $\begin{array}{l}3500^{*} \\
8750^{*}\end{array}$ & \\
\hline & $3600^{*}$ & \\
\hline & 41500 & \\
\hline & 9550 & \\
\hline & & \\
\hline & $\begin{array}{l}\text { Year } 1 \\
\text { (incidence year) }\end{array}$ & $\begin{array}{l}\text { Year } 2 \text { and } \\
\text { following }\end{array}$ \\
\hline \multicolumn{3}{|c|}{ Myocardial infarction (non-fatal definite or possible): } \\
\hline Direct costs/case & 2700 & 550 \\
\hline Indirect costs/case & 4350 & 2700 \\
\hline \multicolumn{3}{|l|}{ Angina pectoris (non-fatal): } \\
\hline Direct costs/case & 1650 & 550 \\
\hline Indirect costs/case & 2700 & 2700 \\
\hline
\end{tabular}

* Direct costs, $\nmid$ costs to health care system, $¥$ indirect costs 
Table 2 Cholesterol, diastolic blood pressure, and smoking in Norsjö 1985-1990 and in the control area (MONICA) 1986 and 1990 (Values are means)

\begin{tabular}{|c|c|c|c|c|c|c|c|c|c|c|}
\hline \multirow[t]{2}{*}{ Risk factor } & \multicolumn{7}{|l|}{ Norsjö } & \multicolumn{3}{|c|}{ Monica $^{16}$} \\
\hline & 1985 & 1986 & 1987 & 1988 & 1989 & 1990 & $p$ & 1986 & 1990 & $p$ \\
\hline \multicolumn{11}{|c|}{ Serum cholesterol $(\mathrm{mmol} / \mathrm{l})$ : } \\
\hline Men & $7 \cdot 0$ & 6.5 & $6 \cdot 5$ & $6 \cdot 4$ & $6 \cdot 2$ & $6 \cdot 0$ & 0.01 & $6 \cdot 4$ & $6 \cdot 3$ & $0 \cdot 27$ \\
\hline Women & $7 \cdot 2$ & $6 \cdot 3$ & $6 \cdot 6$ & $6 \cdot 2$ & $6 \cdot 2$ & $5 \cdot 8$ & 0.03 & $6 \cdot 3$ & $6 \cdot 1$ & 0.01 \\
\hline \multicolumn{11}{|c|}{$\begin{array}{l}\text { Mean diastolic blood pressure } \\
(\mathrm{mm} \mathrm{Hg}) \text { : }\end{array}$} \\
\hline Men & $79 \cdot 0$ & $79 \cdot 1$ & $77 \cdot 5$ & $78 \cdot 7$ & $78 \cdot 8$ & $80 \cdot 7$ & 0.38 & $82 \cdot 0$ & $82 \cdot 7$ & $0 \cdot 20$ \\
\hline Women & $77 \cdot 4$ & $77 \cdot 5$ & $77 \cdot 9$ & $78 \cdot 4$ & $76 \cdot 3$ & $77 \cdot 4$ & 0.66 & $79 \cdot 0$ & $78 \cdot 3$ & $0 \cdot 18$ \\
\hline \multicolumn{11}{|c|}{ Daily smokers (\%): } \\
\hline Men & 26 & 15 & 15 & 19 & 19 & 18 & 0.54 & 23 & 25 & $>0 \cdot 8$ \\
\hline Women & 19 & 27 & 30 & 21 & 26 & 27 & $0 \cdot 48$ & 26 & 26 & $>0.8$ \\
\hline
\end{tabular}

(table 1). The time cost for staff (health care staff and dietician) is the employer's cost and for participants it is set at the employer's cost for an industrial worker. The cost for marketing groceries and for the local authority is based on budget analysis and thorough inquiries and interviews with key actors. The cost of study circles is based on information obtained from the responsible organisations, and the estimated yearly cost corresponds to five circles of 30 hours, each with 10 participants. Calculations of savings attributable to cases prevented were based on Swedish experience. ${ }^{23-26}$ Direct and indirect costs for myocardial infarction have been estimated in connection with randomised controlled trials regarding drug therapy. ${ }^{24-25}$ The major cost components are drugs, diagnostic tests, bed days, outpatient care, home care, and loss of production. Cost estimations for angina pectoris are derived from Swedish cost effectiveness analyses, in particular the recent report from the Swedish Council on Technology Assessment in Health Care regarding moderately raised blood pressure. $^{26}$

We restricted the analysis to 15 years of follow up (1985-99). Costs for the programme that have already been decided upon occurred in the period 1985-94. The number of prevented cases was estimated for the period 1985-98 (1990+8 years). The consequences in the form of years of life saved and other savings, were counted from the year in which the case was prevented until 1999. Costs and savings were discounted at $5 \%$. Years of life saved are reported with and without discounting.

\section{Results}

TRENDS IN RISK FACTORS

Mean serum cholesterol concentrations in the Norsjö population fell by $1.0 \mathrm{mmol} / \mathrm{l}$ in men $(p=0.01)$ and by $1.4 \mathrm{mmol} / 1$ in women $(p=$

Table 3 Predicted risk of coronary heart disease (cumulative incidence 8 years) 1985 and 1990. Bivariate regression $(C I=\alpha+\beta$ year $)$

\begin{tabular}{lllllll}
\hline Sex and age & Intercept & $\beta$ (year) & $p$ (year) & \multicolumn{2}{l}{ Predicted risk } & \multirow{2}{*}{\begin{tabular}{l} 
Difference \\
\cline { 5 - 6 }
\end{tabular}} \\
& & & & $1990-1985$ \\
\hline Men 30 y & 0.0106 & $(-0.0006)$ & 0.0370 & 0.0099 & 0.0067 & -0.0032 \\
Men 40 y & 0.0593 & $(-0.0059)$ & 0.0001 & 0.0533 & 0.0236 & -0.0297 \\
Men 50 y & 0.0965 & $(+0.0004)$ & 0.8712 & 0.0969 & 0.0987 & 0.00184 \\
Men 60 y & 0.1850 & $(-0.0097)$ & 0.0005 & 0.1753 & 0.1267 & -0.04866 \\
Women 30 y & 0.0027 & $(-0.0001)$ & 0.0116 & 0.0026 & 0.0020 & -0.0006 \\
Women 40 y & 0.0109 & $(-0.0003)$ & 0.0931 & 0.0106 & 0.0091 & -0.0015 \\
Women 50 y & 0.0404 & $(-0.0013)$ & 0.0090 & 0.0390 & 0.0323 & -0.0067 \\
Women 60 y & 0.0952 & $(-0.0036)$ & 0.0017 & 0.0916 & 0.0737 & -0.0180 \\
\hline
\end{tabular}

$0.03)$. In the control population no change took place in men and in women the mean level fell by $0.2 \mathrm{mmol} / \mathrm{l}(\mathrm{p}=0.01)$ (table 2$)$. There was no change in blood pressure in either men or in women. The proportion of smokers was quite low but did not change.

PREDICTED TRENDS IN THE RISK OF CORONARY HEART DISEASE

Predicted risks of coronary heart disease followed a plausible sex and age pattern (table 3). In all groups, except in men aged 50 and women aged 40 , the predicted cumulative incidence fell significantly during the period.

The decrease in cumulative incidence corresponded to 4.5 cases (fatal and non-fatal) of cardiovascular disease per year in the Norsjö population in the age range 25 to 64 years.

We could not detect any differences in risk reduction when different social groups were compared. The slope shift variable (social group) was not significant in any sex or age group. (Multivariate regressions models are presented in the appendix.) However, that result does not rule out the possibility of a social pattern. In models which contain only intercept shift variables (social group) we detected a social pattern for men but not for women. Accordingly, in the case of men, the trends specific for social groups have the same slope but are on different levels.

\section{INCREASED MORTALITY DUE TO LOW SERUM CHOLESTEROL}

At the start of the observation period cholesterol levels $\leq 4.15 \mathrm{mmol} / 1$ occurred only sporadically $(<1 \%)$, but during the years 1985-90 the proportion of low cholesterol levels increased significantly to $6.5 \%(p=0.023$ for time trend). Approximately two thirds of these cases identified in 1990 were in the group entering their 31 st year, and two thirds of these were women. In the other age groups these cases were rare, even in 1990 . We estimated that in 1990 of the population of the Norsjö rural district, 35 men (10\%) and 70 women $(25 \%)$ in the age group $25-34$ years had a mean serum cholesterol $\leq 4.15 \mathrm{mmol} / 1$. The annual age and sex specific mortality risk ${ }^{27}$ is approximately $1 \cdot 1 / 1000$ in males and approximately $0 \cdot 5 / 1000$ in females. Under the assumption of a causal relationship, the estimated yearly excess mortality caused by low cholesterol in the Norsjö local government district was 0.02 cases for both men and women. 
Table 4 Sensitivity analysis ( $($ /year of life saved)

\begin{tabular}{|c|c|c|c|c|c|c|}
\hline \multirow[t]{3}{*}{ Discount rate (effects) } & \multicolumn{6}{|c|}{ Alternative } \\
\hline & \multicolumn{2}{|c|}{ "Plateau" } & \multicolumn{2}{|c|}{ "Return" } & \multicolumn{2}{|c|}{$\begin{array}{l}\text { Plateau compensated for } \\
\text { regression dilution bias* }\end{array}$} \\
\hline & $r=5 \%$ & $r=0 \%$ & $r=5 \%$ & $r=0 \%$ & $r=5 \%$ & $r=0 \%$ \\
\hline \multicolumn{7}{|l|}{ Cost components: } \\
\hline Total societal costs, no savings & 12100 & 8250 & 12700 & 8750 & 7750 & 5300 \\
\hline Health care system costs, no savings & 6100 & 4150 & 6400 & 4400 & 3900 & 2650 \\
\hline Total societal costs - savings & 1200 & 850 & 1950 & 1350 & $<0$ & $<0$ \\
\hline Health care system costs - savings & 3700 & 2450 & 4050 & 2800 & 1650 & 1100 \\
\hline "Worst case" 1.5 (total costs) -0.5 (total savings) & 13950 & 9500 & 14900 & 10250 & 6500 & 4400 \\
\hline
\end{tabular}

* Effects are increased with $86 \%$ for men $35-44$ years and with $54 \%$ for men $55-64$ years. The estimates are based on a comparison between predicted effects in the Framingham model $^{10}$ and effects compensated for regression dilution bias in Law et al. ${ }^{11}$

COST EFFECTIVENESS

The effects of the intervention are shown for three different alternatives in table 4 . In the first ("plateau"), the trend towards lower cholesterol levels comes to an end in 1990, but cholesterol remains at the 1990 level during the whole period. In the second ("return"), cholesterol levels revert after 1990, and the fraction of benefit falls from 1.0 in 1995 to 0.5 in 1998. In the third alternative, the "plateau" prognosis is corrected for regression dilution bias. In each of these alternatives, effects are presented with and without discounting. Total societal and health care costs with and without savings are presented. In addition a "worst case" is calculated, where total costs are increased by $50 \%$ and total savings reduced by $50 \%$.

The yearly cost of the programme was $£ 51050$ (table 1). The total cost of the programme for the 10 year trial period and after discounting was estimated to be $£ 363000$. Total savings are dependent upon the effects of the programme and in the "plateau" alternative total savings were estimated to be $£ 326000$, years of life saved were estimated to be 30 for the whole period, and the net cost effectiveness was $£ 1200$ per life year saved (table 4 ). When the maximum fraction of benefit is reached 4.5 cases (fatal and non-fatal) per year are prevented.

The difference between "plateau" and "return" is small. The reason is that the different courses start to diverge in 1995, near the end of the analysis period. Additionally, the discount effect reduces the significance of the divergence. However, in the long run the difference between the two alternatives is likely to be significant.

The most pessimistic combination of effects and costs is the prognosis of the "return" given on the assumption of $50 \%$ higher costs and $50 \%$ lower savings. In this case the ratio is $£ 14900$ per year of life saved. The most favourable combination (compensation for regression dilution bias and total societal net costs) shows greater savings than costs. To facilitate the interpretation of the ratios, the results from some other studies can be mentioned as a reference. A recent report has assessed the cost effectiveness of about 500 life saving interventions. ${ }^{28}$ To improve the comparability between the studies, a homogeneous methodology has been used. For instance, only direct costs and savings are included. The me- dian cost per year of life saved from $\beta$ blockers after myocardial infarction was estimated to be $£ 1300$ and the corresponding cost for cholesterol screening was $£ 4000$. Other examples are coronary artery bypass graft surgery ( $£ 17400$ per year of life saved) and intensive care $(£ 181500$ per year of life saved).

\section{Discussion}

Among well known community interventions, North Karelia has reported both cost-benefit and cost effectiveness analyses. ${ }^{29-31}$ Stanford, Pawtucket, and Heartbeat Wales interventions have only reported cost effectiveness analyses of smoking cessation programmes. ${ }^{32-34}$ Theoretical calculations of cholesterol lowering strategies have also been published. ${ }^{35-37}$ The present analysis is, to our knowledge, the only one based on actual observations of recent date in which the dietary component of a community cardiovascular disease prevention programme has been assessed in cost effectiveness and equity terms.

In the Norsjö intervention, a combined population and individual strategy was used to modify lifestyle. It is not possible to determine with certainty which of these approaches was most effective in bringing about the observed reduction of serum cholesterol in the population. Any effect of the risk factor screening must have been indirect, because each individual was investigated only once during the period covered by the present study. Our knowledge about these indirect effects is incomplete, but one possibility is that effects diffuse from a screened member of a household to the others. A recent, not yet published, study of the Norsjö programme analysed the consequences of educational screening and showed that it strengthens the effects of the community intervention. There is probably a mutual dependence between screening and other measures like information, food labelling, involvement of voluntary organisations, etc. This strategy, which consider screening as a part of the community intervention, has resulted in a profound change in dietary habits and an appreciable lowering of cholesterol concentrations in the Norsjö population. As the cholesterol values remained essentially unchanged in the reference population, it seems that the changes reported here can be specifically attributed to the community intervention programme. It is also worth noting that 
the food labelling system introduced in the Norsjö project was, some years later, introduced as a mandatory national policy by the Swedish Food Administration. With regard to smoking and blood pressure, no change took place in the intervention area. The levels of both these risk factors were relatively low in the beginning of the period while the serum cholesterol value was high. It resulted in a concentration on measures aimed at changing eating habits. The intensity in the anti-smoking work has been low, and the variations in smoking prevalence between the years are likely to be random. This concentration is reflected in an analysis of the mass media coverage of the intervention. During the first three years, 257 articles in daily papers were written. ${ }^{38}$ In $32 \%$ of these articles, eating habits were the main content while smoking was in focus in only $1 \cdot 6 \%$.

The logistic regression models used to estimate cardiovascular morbidity are derived from the Framingham data, ${ }^{10}$ and they assume a dose-response relationship. This supposition is supported by the results of intervention trials, although opinions differ in this respect. The models do not take into account possible interaction between risk factors and they may therefore underestimate the effects of reductions in the risk factor levels of populations. ${ }^{39}$

The logistic model consists of two parts, the intercept term and the regression coefficients. The underlying incidence rate in the population from which the logistic equation was derived is reflected in the magnitude of the constant intercept term. ${ }^{40}$ Therefore, a logistic equation from a population with high incidence would be expected to overestimate the number of events for a population with a lower incidence, and vice versa. ${ }^{4142}$ The validity of the Framingham risk function in a Swedish population has been assessed in a report from the Swedish
Council on Technology Assessment in Health Care. ${ }^{26}$ The Framingham risk function was compared with functions derived in two studies from the Gothenburg region (the study of men born in $1913^{43}$ and a study of Swedish women ${ }^{44}$ ). For both men and women, the comparison shows that the Framingham function predicts substantially higher cumulative incidence when the risk factor burden is low. When the burden is high, Framingham and the Swedish functions predict approximately the same cumulative incidence. If the Framingham function is used to predict the decline in cumulative incidence caused by a reduction in smoking or blood pressure it can, as we judge it, result in an over- or underestimation. It all depends on the slope of the risk function in the segment where the risk burden changes. However, the authors of the report from the Council of Technology Assessment judge the Framingham function to be useful in their cost effectiveness analysis of moderately raised blood pressure, despite the fact that they expect an overestimation of incidence when it is applied to the Swedish population in general. As mentioned earlier, the Norsjö area has an $80 \%$ excess mortality rate in cardiovascular disease for men compared with the national average, and the MONICA region of northern Sweden has an approximately $50 \%$ higher age standardised annual rate of coronary events for men than in the Gothenburg region. ${ }^{19}$ Therefore, it seems likely that the Framingham function will fit the Norsjö population better than the Gothenburg or the national population. Furthermore, the advantages of the Framingham function is that it covers a wide range of ages and both sexes. ${ }^{45}$

Our estimates seem to be conservative when it is considered that the direct effects of screening, the interaction effects between risk factors, and the potential diffusion effects outside the

Appendix

Multivariate regressions with social class as interceptshift variable and social class* year as slope shift variables

\begin{tabular}{|c|c|c|c|c|c|c|c|c|}
\hline Variable & $\begin{array}{l}\text { Model } 1 \\
\text { Men } 30 y\end{array}$ & $\begin{array}{l}\text { Model } 2 \\
\text { Men } 40 y\end{array}$ & $\begin{array}{l}\text { Model } 3 \\
\text { Men } 50 y\end{array}$ & $\begin{array}{l}\text { Model } 4 \\
\text { Men } 60 y\end{array}$ & $\begin{array}{l}\text { Model } 5 \\
\text { Women } 30 y\end{array}$ & $\begin{array}{l}\text { Model } 6 \\
\text { Women } 40 y\end{array}$ & $\begin{array}{l}\text { Model } 7 \\
\text { Women } 50 y\end{array}$ & $\begin{array}{l}\text { Model } 8 \\
\text { Women } 60 y\end{array}$ \\
\hline \multicolumn{9}{|l|}{ Intercept: } \\
\hline Parameter estimate & 0.009196 & 0.057726 & 0.092985 & $0 \cdot 182814$ & 0.002740 & $0 \cdot 011621$ & 0.035797 & 0.098201 \\
\hline SE & 0.00288296 & 0.00613872 & 0.01412720 & 0.02274927 & 0.00041637 & 0.00108533 & 0.00398482 & 0.00679863 \\
\hline $\mathrm{T}$ & $3 \cdot 190$ & $9 \cdot 404$ & $6 \cdot 582$ & 8.036 & $6 \cdot 582$ & $10 \cdot 707$ & 8.983 & $14 \cdot 444$ \\
\hline $\mathrm{p}$ & 0.0017 & 0.0001 & 0.0001 & 0.0001 & 0.0001 & 0.0001 & 0.0001 & 0.0001 \\
\hline \multicolumn{9}{|l|}{$\begin{array}{l}\text { Year: } \\
(1985-1990)\end{array}$} \\
\hline Parameter estimate & -0.000494 & -0.006548 & -0.000845 & $-0 \cdot 010464$ & -0.000108 & -0.000417 & -0.001259 & -0.004273 \\
\hline SE & $0 \cdot 00075481$ & 0.00169190 & 0.00352481 & 0.00606455 & 0.00010402 & 0.00028204 & 0.00097270 & 0.00210883 \\
\hline $\mathrm{T}$ & -0.654 & $-3 \cdot 870$ & $-0 \cdot 240$ & $-1 \cdot 725$ & -1.034 & -1.478 & $-1 \cdot 295$ & $-2 \cdot 026$ \\
\hline \multicolumn{9}{|l|}{ Social class 2 : } \\
\hline Parameter estimate & 0.002819 & -0.008951 & -0.000884 & 0.025058 & -0.000273 & -0.002067 & -0.004291 & -0.021817 \\
\hline SE & 0.00341048 & 0.01152007 & 0.02280953 & 0.02954324 & 0.00073385 & 0.00258213 & 0.00764352 & 0.01391911 \\
\hline $\mathrm{T}$ & $0 \cdot 827$ & -0.777 & -0.039 & 0.848 & -0.372 & -0.800 & -0.561 & -1.567 \\
\hline $\mathrm{p}$ & 0.4097 & 0.4382 & 0.9691 & 0.3976 & 0.7107 & 0.4246 & 0.5753 & 0.1189 \\
\hline \multicolumn{9}{|l|}{ Social class 3 : } \\
\hline Parameter estimate & 0.001094 & $0 \cdot 015886$ & 0.010796 & -0.011503 & 0.000100 & -0.001075 & 0.006585 & 0.000329 \\
\hline SE & 0.003373 & 0.01118573 & 0.02056683 & 0.02743600 & 0.00048767 & 0.00144835 & 0.00462414 & 0.00909951 \\
\hline $\mathrm{T}$ & 0.324 & 1.42 & 0.525 & -0.419 & $0 \cdot 206$ & -0.742 & 1.424 & -0.036 \\
\hline $\mathrm{p}$ & 0.7460 & $0 \cdot 1574$ & 0.6004 & 0.6756 & 0.6832 & 0.4592 & 0.1564 & 0.9712 \\
\hline \multicolumn{9}{|l|}{ Social class $2 *$ year } \\
\hline Parameter estimate & -0.000694 & 0.004072 & 0.005560 & -0.004587 & 0.00002944 & 0.000412 & 0.002693 & 0.006158 \\
\hline SE & 0.00091483 & 0.00306355 & 0.00573628 & 0.00776420 & 0.00016533 & 0.00065704 & 0.001790 & 0.00423312 \\
\hline $\mathrm{T}$ & -0.759 & $1 \cdot 329$ & 0.969 & -0.591 & $0 \cdot 178$ & 0.627 & 1.505 & 1.455 \\
\hline $\mathrm{p}$ & 0.4490 & $0 \cdot 1856$ & $0 \cdot 3339$ & 0.5555 & 0.8589 & 0.5313 & $0 \cdot 1344$ & $0 \cdot 1476$ \\
\hline \multicolumn{9}{|l|}{ Social class $3^{*}$ year } \\
\hline Parameter estimate & 0.000122 & -0.002666 & -0.000632 & 0.004723 & -0.00005167 & 0.000194 & -0.000293 & 0.000039575 \\
\hline SE & 0.00088875 & 0.00300838 & 0.00528811 & 0.00729694 & 0.00012633 & 0.00038668 & 0.00115948 & 0.00259956 \\
\hline $\mathrm{T}$ & 0.137 & -0.886 & -0.119 & 0.647 & -0.409 & 0.501 & -0.253 & 0.015 \\
\hline $\mathrm{p}$ & 0.8912 & $0 \cdot 3767$ & 0.9051 & 0.5184 & 0.6832 & 0.6171 & 0.8009 & 0.9879 \\
\hline
\end{tabular}


intervention area are excluded from the analyses. On the other hand, there is a general trend towards lower serum cholesterol values in women in the reference area, which we have not compensated for in our calculations. However, fewer than a quarter of the prevented cases in our study are women, and the reduction in the intervention area was seven times larger $(-1.4 \mathrm{mmol} / 1$ and $-0.2 \mathrm{mmol} / 1$ respectively) than in the reference area. This means that the total number of prevented cases may be overestimated by no more than $3-4 \%$.

Our data indicate that any negative effects of reducing cholesterol levels in the community are negligible in comparison with the beneficial effects. They also show that in the Norsjö prevention programme, all social groups benefit to a similar extent. Furthermore, they suggest that community intervention programmes are much more effective in reducing cardiovascular disorders, at least in the short term, if they concentrate on upper middle aged groups. Thus, in the 55-64 year age range, it is estimated that eight to nine cardiovascular events have been avoided each year per 1000 men in the Norsjö intervention programme. This is achieved at a very reasonable cost per event avoided.

1 Brännström I, Rosén $\mathrm{M}$, Wall S, Weinehall L. Local health planning and intervention - the case of a Swedish muplanning and intervention - the case of a Swedish mu-

nicipality. Scand frim Health Care 1988(Suppl 1): $87-64$. $S$. Changing social patterns of risk factors for cardiovascular disease in a Swedish community intervention programme. Int $\mathcal{f}$ Epidemiol 1993;22:1026-37.

3 Hulley SB, Walsh JMB, Newman TB. Health policy on blood cholesterol - time to change directions. Circulation 1992;86:1026-9.

4 Jacobs D, Blackburn $H$, Higgins $M$, Reed D, Iso $H$, McMillan G et al. Report of the conference on low blood cholesterol: mortality associations. Circulation 1992;86: 1046-60

5 Muldoon MF, Manuck SB, Matthews KA. Lowering cholesterol concentrations and mortality: a quantitative review lesterol concentrations and mortality: a quantitative re
of primary prevention trials. BMF 1990;301:309-14.

6 Holme I. An analysis of randomized trials evaluating the effect of cholesterol reduction on total mortality and coreffect of cholesterol reduction on total mortality and cor-
onary heart disease incidence. Circulation 1990;82:191624 .

7 Law MR, Thompson SG, Wald NJ. Assessing possible hazards of reducing serum cholesterol. BMF 1994;308: 373-9

8 Smith GD, Pekkanen J. Should there be a moratorium on the use of cholesterol lowering drugs? $B M F$ 1992;304: 431-4.

9 Ravnskov U. Cholesterol lowering trials in coronary heart disease: frequency of citation and outcome. BMF 1992; 305:15-19.

10 Kannel WB, Wolf PA, Garrison RJ. (eds). The Framingham study. An epidemiological investigation of cardiovascular disease. Bethesda: National Institutes of Health, 1987. NIH Publication No 87-2284.

11 Law MR, Wald NJ, Wu T, Hacksaw A, Bailey A. Systematic underestimation of association between serum cholesterol concentrations and ischaemic heart disease in obserconcentrations and ischaemic heart disease in obser-
vational studies: data from the BUPA study. $B M \mathcal{F} 1994$; vational studie

12 Smith GD, Shipley MJ, Marmot MG, Rose G. Plasma cholesterol concentration and mortality. The Whitehall study. $\mathcal{F} A M A$ 1992;267:70-76.

13 Scandinavian Simvastin Survival Study Group: Randomised trial of cholesterol lowering in 4444 patients with coronary heart disease: the Scandinavian simvastin survival study (4S). Lancet 1994;344:1383-9.

14 Keys A, Arvanis C, Blackburn $\mathrm{H}$, et al. Seven countries. A multivariate analysis of death and coronary heart disease. Cambridge, MA and London: Harvard University Press, 1980.

15 Statistics Sweden. Swedish socio-economic classification (SEI). Stockholm: Statistics Sweden, 1982. Reports on Statistica Co-ordination 1982:4

16 Huhtasaari F, Asplund K, Wester P-O. Cardiovascular risk factors in the northern Sweden MONICA study. Acta Med Scand 1988;224:99-108.
17 Pindyck RS, Rubinfeld DL. Econometric models and economic forecasts. 3rd ed. Singapore: McGraw-Hill, 1991.

18 Freund RJ, Litell RC. SAS system for regression. Cary, NC: SAS Institute Inc, 1992

19 Tunstall-Pedoe H, Kuulasmaa K, Amouyel P, Arveiler D, Rajakangas A-M, Pajak A. Myocardial infarction and coronary deaths in the World Health Organizations MONICA project. Circulation 1994;90:583-611.

20 Law MR, Wald NJ, Thompson SG. By how much and how quickly does reduction in serum cholesterol concentration lower risk of ischaemic heart disease: $B M \mathcal{F} 1994 ; 308$ : 362-72.

21 MacMahon S, Peto R, Cutler J, et al. Blood pressure, stroke, and coronary heart disease. Part 1 , prolonged differences in blood pressure: prospective observational studies corin blood pressure: prospective observational studies cor765-74.

22 Lindholm L, Rosén M, Hellsten G. Are people willing to pay for a community-based preventive program. International fournal of Technology Assessment in Health Care 1994;10: 317-24.

23 Johannesson M, Hedbrant J, Jönsson B. A computer simulation model for cost-effectiveness analysis of cardiovascular disease prevention. Linkoping: Linkoping University, 1991. Centre for Medical Technology Assessment Report 3.

24 Levin L-Ä, Jönsson B. Cost-effectiveness of thrombolysis: a randomized study of intravenous rt-PA in suspected myocardial infarction. Eur Heart 7 1992;13:2-8.

25 Olsson G, Levin L-Â, Rehnqvist N. Economic consequences of postinfarction prophylaxis with $\beta$ blockers: cost-effectof postinfarction prophylaxis with $\beta$ blockers:
iveness of metoprolol. $B M F 1987 ; 294: 339-42$.

26 The Swedish Council on Technology Assessment in Health Care. Måttligt förhöjt blodtryck. Stockholm: Swedish Council on Technology Assessment in Health Care, 1994. Report 121 (Summary available in English, "Moderately elevated blood pressure".)

27 Statistical yearbook of Sweden, 1992. Stockholm: Nordstedts Tryckeri AB, 1992

28 Tengs TO, Adams M, Pliskin JS, Safran DG, Siegel JE, Weinstein MC, Graham JD. Five-hundred life-saving interventions and their cost-effectiveness. Boston: Center for Risk Analysis, Harvard School of Public Health, 1994.

29 Nissinen A, Tuomilehto J, Kottke TE, Puska P. Costeffectiveness of the North-Karelia hypertension program 1972-1977. Med Care 1986;24:767-80.

30 Nissinen A, Tuomilehto J, Enlund H, Kottke TE. Costs and benefits of community programmes for the control of hypertension. Fournal of Human Hypertension 1992;6: of hyp.

31 Kottke TE, Puska P, Feldman R, Salonen JT, Tuomilehto JA. A decline in earnings losses associated with a community based cardiovascular disease prevention project. Med Care 1982;20:663-75.

32 Altman DG, Flora JG, Fortman SP, Farquar JW. The costeffectiveness of three smoking cessation programs. $A m \mathcal{F}$ Public Health 1987;77:162-65.

33 Nelson DJ, Lasater TM, Niknian M, Carleton RA. Cost effectiveness of different recruitment strategies for selfhelp smoking cessation programs. Health Education $\mathrm{Re}$ search 1989;4:79-85.

34 Phillips CJ, Prowle MJ. Economics of a reduction in smoking: case study from Heartbeat Wales. $\mathcal{f}$ Epidemiology ing: case study from Heartbeat Wal

35 Berwick DM, Cretin S, Keeler EB. Cholesterol, children and heart disease: an analysis of alternatives. New York/Oxford: Oxford University Press, 1980

36 Kristiansen IS, Eggen AE, Thelle DS. Cost effectiveness of incremental programmes for lowering serum cholesterol concentration: is individual interventions worth while? BMF 1991;302:1119-22

37 Kinosian B, Eisenberg JM. Cutting into cholesterol. $\mathcal{F} A M A$ 1988;259:2249-54

38 Brännström I, Lindblad I-B. Mass communication and health promotion: The power of media in the public opinion. Health Communication 1994;6:21-36.

39 Perkins KA. Interactions among coronary heart disease risk factors. Annals of Behavioral Medicine 1989;11:3-11.

40 Kinlay S, O'Connel D, Evans D, Francis L. The validity of estimating heart disease reduction from a Framingham estimating heart disease reduction from a Framin

41 Gordon T, Kannel WB. Multiple risk functions for predicting coronary heart disease: The concept, accuracy, and application. Am Heart $\mathcal{f}$ 1982;103:1031-39.

42 Leaverton PE, Sorlie PD, Kleinman JC, Dannenberg AL, Ingster-Moore I, Kannel WB, Cornoni-Huntley JC. Representativeness of the Framingham risk model for coronary heart disease mortality: a comparison with a national cohort study. F Chronic Dis 1987;40:775-84.

43 Svärdsudd K, Tibblin G. Mortality and morbidity during 13.5 years' follow-up in relation to blood pressure. The study of men born in 1913. Acta Med Scand 1979;205: 483-92.

44 Sigurdsson JA, Bengtsson C, Lapidius L et al. Morbidity and mortality in relation to blood pressure and antihypertensive treatment. A 12-year follow-up study of a population sample of Swedish women. Acta Med Scand 1984;215:313-22.

45 Chambless LE, Dobson AJ, Patterson CC, Raines B. On the use of a logistic risk score in predicting risk of coronary heart disease. Stat Med 1990;9:385-96. 